\title{
Assessment of the uncertainty associated with the energy indicator ${ }^{\text {is }}$
}

\author{
Carlos Mendes*, Leonardo Silva de Souza, Ricardo Kalid, Karla Esquerre, Asher Kiperstok \\ Universidade Federal da Bahia, Salvador-Ba, Brazil
}

\section{A R T I C L E I N F O}

\section{Article history:}

Received 27 October 2010

Accepted 13 April 2011

\section{Keywords:}

Energy indicator

Evaluation of uncertainty

Environmental performance

\begin{abstract}
A B S T R A C T
Environmental indicators have been constructed and used as a tool for measuring environmental performance for various purposes in the industrial environment including that of decision-making. However, few studies in the literature address the issue of the quality of the data used for the construction of these indicators, and one of the factors neglected is the uncertainty associated with them. This paper deals with a case study on the uncertainty in the energy indicators of a petrochemical industry in Brazil. In this study, there is an examination of the components involved in making the calculation of energy indicators, as well as their uncertainties. The end result is the development of a methodology that can be used for assessing the uncertainty of the indicators. The evaluation of this uncertainty shows a value greater than appropriate for the intended use of the indicator. In order to reduce this uncertainty, an attempt has been made to point out the most striking features that require investment in human and economic resources, such as improvement in the measurements and implementation of new measurers at critical points.
\end{abstract}

(c) 2011 Elsevier Ltd. All rights reserved.

\section{Contents}

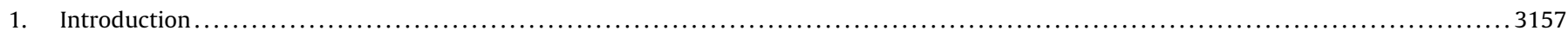

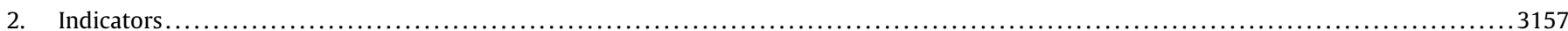

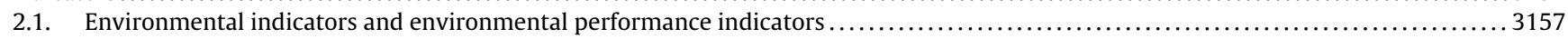

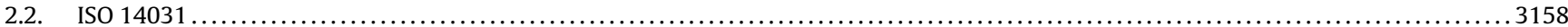

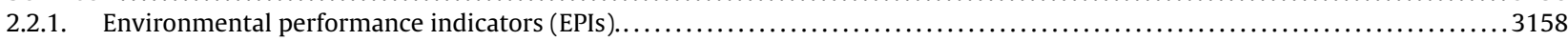

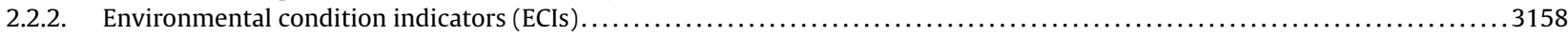

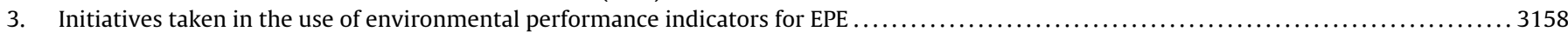

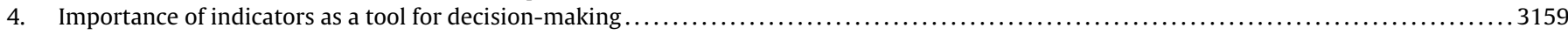

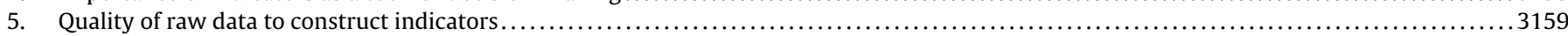

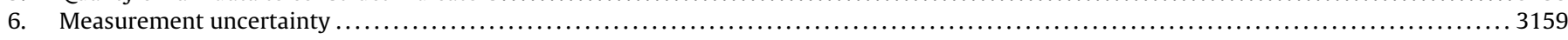

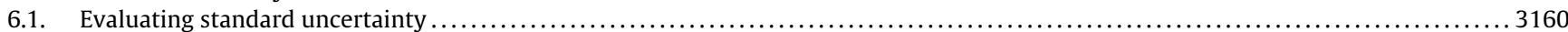

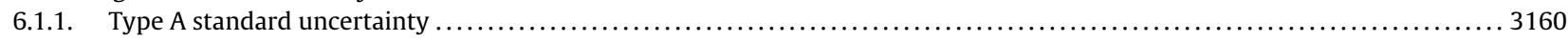

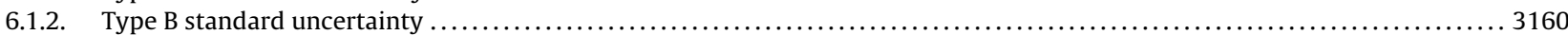

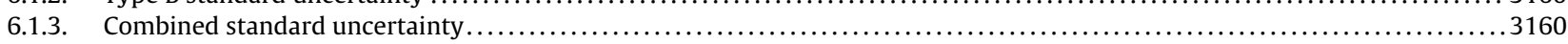

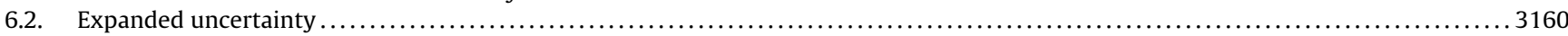

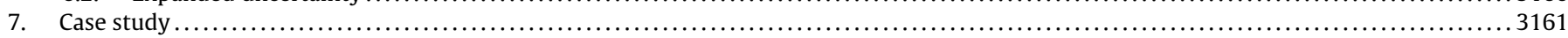

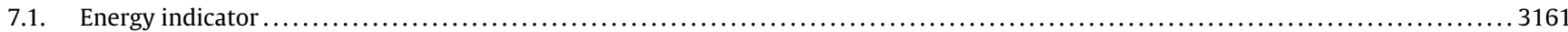

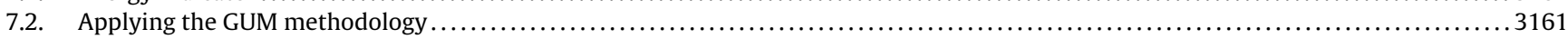

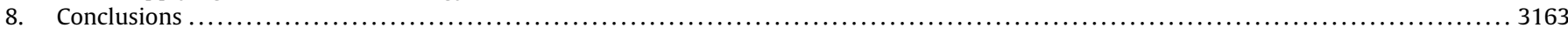

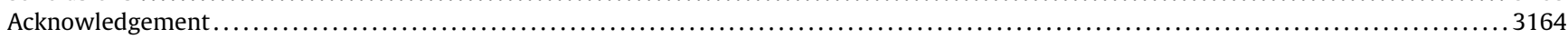

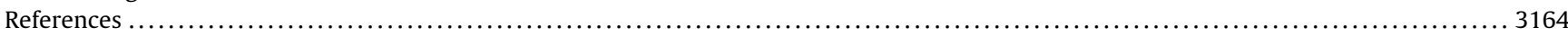

\footnotetext{
is This work was a collaborative effort between University and Industrial.

* Corresponding author.

E-mail addresses: carllosmendez@gmail.com (C. Mendes), leosouza@ufba.br (L.S. de Souza), kalid@ufba.br (R. Kalid), karlaesquerre@ufba.br (K. Esquerre), asher@ufba.br (A. Kiperstok).
} 


\section{Introduction}

Many organizations are seeking ways to understand, demonstrate, improve and measure their environmental performance [1]. According to the ISO 14031, this can be achieved effectively by dealing with the features of its activities, such as products and services which have a significant impact on the environment. This impact can be measured through related indicators, such as the amount of energy consumed in manufacturing the products. With regard to industrial activities, the indicators were traditionally related to economic factors, such as cost, production and process efficiency, while failing to focus on environmental areas [2]. However, the efficient use of water and energy for their industrial units has led the industry to change its attitudes to already established schemes which, due to their operational success in terms of the need to optimize the use of natural resources, had not been questioned before [3].

Environmental performance can be defined as the "measurable results of the ability of an organization to handle environmental factors which can be, defined as those elements of an organization's activities, products or services that can interact with the environment, and have an impact on it" [4]. Environmental performance evaluation (EPE) is a process of internal management designed to facilitate decision-making, by making a selection of indicators to provide information for comparing the environmental performance of the past and present, and thus predict the possible trends in the future of an organization.

The need for information about organizational performance has arisen for several reasons: compliance cost reduction regarding future requirements, the adoption of voluntary environmental codes, lower operating costs, improved relations with stakeholders, and finally, an awareness of the environmental visibility of the company as a competitive advantage [3]. The indicators can be used as an important measurement tool to display this information in a clear and objective way, to help meet these requirements [5]. As such, the indicators are the main tools of the ISO 14031 for providing information about the environmental performance of organizations [6-16]. Lately, environmental indicators have thus been constructed and used as a tool to support environmental management organizations $[9,17-19,13,20]$. One factor that is often neglected is the uncertainty of the measurements applied to the indicators, as well as the raw data used for their construction $[21,19]$. However, Perotto et al. [19] state that the uncertainty has affected the raw data and this is a crucial issue, since the indicators may provide a distorted image of the results when applied to environmental factors.

This article sets out a methodology for calculating the energy indicators and estimates of uncertainty. The proposed methodology is based on the method outlined by GUM Guide to the expression of uncertainty in measurement published by the International Organization for Standardization ISO (GUM [22]). This methodology was used to examine a large petrochemical industry located in the Industrial Complex of Camaari, in Bahia, Brazil. The results tend to support the company's strategic decisions with regard to the calculation of indicator values.

\section{Indicators}

There are several definitions and characteristics of indicators that can be found in the literature. According to Perotto et al.[19], indicators are variables that summarize or simplify relevant information about the state of a complex system. Cantarino [23] defines indicators as useful information for decision-making, which means that one can infer the quality of a particular indicator by the quality of the information provided. According to Cardoso [4], indicators can be used as an important measurement tool to express information, clearly and objectively, and thus help meet this demand. They are management control tools that provide support for decision-making which are based on the relevant information and summarized in concise illustrative statements. The indicator can be considered a variable an operational representation of an attribute (quality, characteristic, property) of a system [24]. It is usually calculated on the basis of historical observations and reflects past behavior; this enables indicators to be used in the detection of trends, benchmarking and reporting on operational conformity with regard to any restrictions imposed and the achievement of best practices in environmental management.

Indicators can provide either qualitative or quantitative information. Both are necessary and a complementary means of showing the environmental, economic and social performance of the organizations. Although the use of quantitative indicators is highly recommended, it is not always possible to apply them to measure performance, especially in the social field. Many social issues are subjective and the measurement of performance is not easily quantifiable [25]. Quantitative indicators are well-defined components and are thus more easily reproduced over time and have greater reliability in their information, while qualitative indicators are more susceptible to variations.

According to Veleva and Ellenbecker [24] constructing an indicator involves adding a unit of measurement, the period of measurement, and boundaries. Environmental indicators can be shown in either absolute or relative terms, for example, as an expression that provides information that can be used to compare an organization's environmental performance with its production. As well as these two forms of presentation, the standard [23,26,1,10,27,24]. As well as these two forms of presentation, the standard [28] provides three examples of ways that environmental indicators can be classified:

- Indexed - data or descriptive information converted into units or in a form that links the information to a chosen standard or frame of reference that is expressed in percentage (\%) terms.

- Aggregate - data or descriptive information of the same type but collected from different sources and expressed as a combined value, thus providing one or more environmental parameters of interest.

- Weighted - expresses the degree of relative importance or importance of the indicators of environmental performance.

Hence, the use of indicators is a part of an ongoing evolutionary process that involves obtaining knowledge and requires a survey, analysis and interpretation of the data and processes. This can lead to transformation in the company by raising awareness and entering a more worthwhile dialogue with stakeholders [24]. When collecting data that will supply the indicators with information, it is necessary to take into account its reliability, availability and validation in both phenomenological and statistical areas.

\subsection{Environmental indicators and environmental performance indicators}

A number of definitions of environmental indicators have been cited by different organizations. In the case of EPA (2003) the North American Environmental Protection Agency, an environmental indicator is a numerical value derived from actual measurements of a pressure, state or ambient condition, exposure or human health or ecological condition over a specified geographic domain, whose trends over time represent or draw attention to underlying trends in the condition of the environment [29]. UNEP (2009) the United Nations Environment Programme defines environmental indicators as $a$ way to improve the delivery of information for decision-making [30]. While for the Organization for Economic Cooperation and Devel- 
opment, it is an essential tool for tracking environmental progress, supporting policy evaluation and informing the public [31].

In the case of an industrial environment, environmental indicators are important tools for measuring and displaying the results that enable life cycle assessment of the product to be made [32] This can help industry to obtain optimal operating points with regard to its environmental performance and support advances made in industry by taking action that can lead to effective improvements in sustainability. Looking at the issue in greater detail, according to Jasch [10] and Tsoulfas and Pappas [33], environmental performance indicators can be used in the following ways:

- Highlighting the potential for optimization.

- Achieving the environmental objectives of the company.

- Identifying market opportunities and the scope for cost reduction.

- Evaluating the environmental performance of different companies (benchmarking).

- Acting as a communication tool for environmental reporting.

- Providing technical support for environmental management systems.

A further feature of the indicators is that they:

- Should be measurable, and thus verifiable.

- Should help improve the decision-making process, after carrying out an overall assessment of a company's operations, products and services.

- Should also enhance benchmarking and monitoring over time, since companies have to modify their practices from time to time.

Tsoulfas and Pappis [33] highlight two difficulties that have been encountered with the construction and use of environmental performance indicators. The first is the collection of data, especially when large systems are being examined, and the second is lack of data quality, leading to different approaches being adopted and a feeling that they do not produce a true and fair account of a process.

\subsection{ISO 14031}

This standard describes two general categories of indicators for environmental performance evaluation (EPE).

\subsubsection{Environmental performance indicators (EPIs).}

EPIs can be classified as:

- Management Performance Indicators (MPIs): these are types of EPIs that provide information on the efforts made by the management to influence the environmental performance of the organization's operations.

- Operational Performance Indicators (OPIs): these are types of EPIs that provide information about the environmental performance of the organization's operations.

\subsubsection{Environmental condition indicators (ECIs)}

ECIs provide information that can help the organization to have a better understanding of the impact or potential impact of its environmental policies and thus help in the planning and implementation of the EPE. Table 1 shows some examples of indicators used for assessing the environmental performance found in standard ISO 14031.
Table 1

Examples of indicators for EPE (ISO 14031).

\begin{tabular}{|c|c|c|}
\hline Category & Classification & Examples \\
\hline \multirow[t]{2}{*}{ EPIs } & MPIs & $\begin{array}{l}\text { Operating and capital costs associated with the } \\
\text { environmental aspects of a process or product } \\
\text { Return on investment in environmental } \\
\text { improvement projects } \\
\text { Number of objectives and targets } \\
\text { environmentally achieved }\end{array}$ \\
\hline & OPIs & $\begin{array}{l}\text { Quantity of energy used per year or per unit of } \\
\text { product } \\
\text { Quantity of water reused } \\
\text { Quantity of water per unit of product }\end{array}$ \\
\hline ECIs & ECls & $\begin{array}{l}\text { Concentration for monitoring of a given } \\
\text { contaminant, in air, at selected sites } \\
\text { Dissolved oxygen in receiving bodies } \\
\text { Concentration of selected nutrients in the soil } \\
\text { adjacent to the premises of the industry }\end{array}$ \\
\hline
\end{tabular}

\section{Initiatives taken in the use of environmental performance indicators for EPE}

Diakaki et al. [7] recommends a method based on the principles of risk assessment (a basic technique in environmental protection and management), to assist organizations in selecting the most appropriate indicators for the assessment procedures of their environmental performance. The main advantage of applying this method is that it makes it easier to carry out an evaluation of environmental performance by putting emphasis on one of the most important steps required to decide what specific indicators should be taken into account. Hermann et al. [9] use a combination of three tools (LCA - analysis of the life cycle, MCA - multi-criteria analysis and EPIs - environmental performance indicators) to provide information about the evaluation of environmental impacts applied in improving the environmental performance of an pulp industry in Thailand. Integrating these three tools allows for an assessment which is complete in that it includes parts of the production chain that are outside the boundaries of the industrial system itself, resulting in indicators which are easy to interpret for policy purposes with readily available information. From a methodological point of view, a disadvantage of this new combination of tools may be the fact that the LCA is not fully carried out. However, a full LCA may not be needed for companies that are primarily interested in the part of the system they control, i.e. the on-site processes as well as the preceding production chain on which they have influence through their choice of suppliers. Saengsupavanich et al.[13] used environmental performance indicators to assess the environmental performance of the Industrial Estate Authority of Thailand (IEAT) as a means of regulating the Map Ta Phut (MTP) port and industrial estate. Johnston and Smith [11] put forward a model based on two methods to devise indicators that can be applied by managers of water companies. The first method consisted of semi-structured interviews with managers of the water company. The second consisted of a survey conducted by e-mail with the managers of the environmental industry. The model suggested that there was a need to investigate the link between environmental issues, environmental management systems and the development of indicators, types of goals and objectives, and management style and the use of indicators as a tool for public relations. Henri and Journeault [8] mention the importance of the following: measuring environmental performance through the use of environmental performance indicators to support organizations in communicating environmental strategies, supporting and ensuring Environmental Compliance, assisting in obtaining and maintaining ISO 14001 certification, adopting formally complex environmental processes and procedures and providing data for external reporting in manufacturing companies in Canada. BertrandKrajewski et al. [21] conducted an assessment 
of uncertainties with regard to performance indicators, through two case studies into stormwater facilities. Both cases show that the uncertainties are very significant and should be included in the calculation and use of performance indicators. These researchers point out that there has been little research into the use of environmental performance indicators for decision-making which are based on the quality of the raw data.

\section{Importance of indicators as a tool for decision-making}

According to Andrade [34], one of the factors that can complicate rational decision-making is uncertainty. Most decisions, particularly the most important, are made on the basis of some kind of prediction, which, in itself, puts the uncertainty factor into the decision process. Even if the problem does not require any evaluation to be made, another complicating factor is the lack of information. Thus one of the main difficulties encountered by decision-makers in companies - such as questions concerning how to invest and why, how to prioritize and what the returns on investments in the environment should be - is the lack of knowledge and information available for dealing with complex issues. Olsthoorn et al. [12] argue that decision-making and the management of complex issues in the industrial environment, requires the use of indicators to represent what these issues are. Thoresen [14] states that in practice environmental performance indicators can be used for decision-making by interested parties, both outside the organization (at a macro level) and at different levels of organization within the company (at a micro level) and that this can gradually reduce the harmful environmental impacts of products and processes. External stakeholders need a set of environmental performance indicators (applied on a large scale) to enable them to exert pressure on businesses and thus ensure that improvements are planned and implemented on an ongoing basis. Berkhout et al. [6] argues that environmental performance indicators can be used by stakeholders in business in the following ways:

- Banks and insurers can examine the environmental performance indicators to assist companies in evaluating long-term economic risks.

- Fund managers use environmental criteria to address demands for the incorporation of environmental concerns and ethical issues in investment decisions.

- Those responsible for policymaking can evaluate the effectiveness of different policy devices in improving the environmental performance of companies.

- Researchers can analyze the design and trends to improve our understanding of the causes of high and low environmental performance.

\section{Quality of raw data to construct indicators}

According to BertrandKrajewski et al. [21], only a few studies about performance indicators address the following issues:

- Evaluation of the quality and the credibility of results obtained through an estimation of performance indicators.

- Evaluation of the impact of the quality of the indicators on decisions that have to be made.

Nordheim and Barrasso [18] and Von Bahr et al. [32] assess the importance of data quality indicators to measure the operating performance for three types of emissions, dust, $\mathrm{NO}_{x}$ and $\mathrm{SO}_{2}$ as a limiting factor for benchmarking and to carry out an external evaluation of six cement plants in Sweden, Norway and Finland. The author highlights the importance of the need to take into account the reliability, availability and ability to validate the scientific and statistical data when comparing the environmental performance of two companies.

Perotto et al. [19] state that measuring the organization's environmental performance remains one of the great difficulties for the organization and certification/bodies responsible. The question of the link between measurement uncertainty and the indicator can be a competitive differentiator, because the environmental performance indicators are used by companies for benchmarking which means that environmental performance indicators which have a lower degree of uncertainty will inspire greater confidence among the stakeholders. When there is a maximum or minimum level for the indicator, whether established by legislation or otherwise, the degree of uncertainty becomes an essential factor in assessing the likelihood of error or accuracy in decision-making. The uncertainty of the indicator is also a valuable tool to use to allow the key components that influence the final quality of the indicators to be identified. On the other hand, if the degree of uncertainty of the indicator is unknown, a change in its value may be due to natural variability in the process of planning and implementing changes and this can increase the probability of making wrong decisions.

\section{Measurement uncertainty}

The term uncertainty is closely linked to the concept of doubt. The uncertainty of the measurement is nothing more than a doubt regarding the measurand (a particular quantity that is subject to measurement) at the time when the measurement is carried out. Uncertainty can be understood as a measure of quality measurement [35]. Thus, it can be said that the smaller the uncertainty, the better the quality of the measurement. It is evident that the measurement result is the best evaluation of the measurand, and that all the components of uncertainty, including those arising from systematic effects, such as components associated with corrections and reference standards, contribute to the dispersion.

The uncertainty of the result of a measurement reflects the lack of a complete knowledge of the value of the measurand. The result of a measurement after correction of the known systematic effects, is still only an evaluation of the value of the measurand because of uncertainty arising from the extent of random effects and the imperfect correction of the result of systematic effects, both of which can never be fully known. Therefore, the result of measuring or calculating a magnitude represents only an approximation of the value of the measurand and to be complete it must be accompanied by a statement of measurement uncertainty. According to the International Vocabulary of Basic and General Terms in Metrology VIM [36], the uncertainty of measurement generally comprises many components. Some of these components can be evaluated on the basis of the statistical distribution of the results of a series of measurements and can be characterized by experimental standard deviations. The other components, which can also be characterized by standard deviations, are evaluated by the assumed probability distribution, based on experience or other information. To avoid the occurrence of duplications of the uncertainties associated with measuring, it is necessary to adopt a structured and detailed procedure. VIM recommends the use of the cause and effect diagram, also known as the Ishikawa diagram, to achieve this goal.

Several methods have been used to determine the measurement uncertainty. One method that is widely accepted by accreditation bodies, is GUM which lays down general rules that must be adhered to by metrologists involved in quality measurement from the shop floor to in-depth research, to evaluated the measurement uncertainty of the measurand. In addition, GUM sets out a procedure, which is widely believed to propagate uncertainties in inputs (measured variables) for the output quantities (variables that are 
calculated through a model). The measure is generally straightforward in evaluating the indicator when it is absolute, and the uncertainty of the input is the very uncertainty of the indicator. On the other hand, when these are indicators of two or more input quantities, they are measured directly and their uncertainties must be propagated to the output quantity; in other words, the uncertainty of the relative indicator always of the in the form of the composition of the uncertainties of the input.

\subsection{Evaluating standard uncertainty}

When evaluating the measurement uncertainty, GUM reflects the propagation of the uncertainties of the influence quantities through a mathematical model that represents the measurand:

$Y=f\left(X_{1}, X_{2}, \ldots, X_{N}\right)$

where $Y$ represents the output quantity and $X_{i}$ the input quantities. Each input evaluated and its associated combined standard uncertainty are obtained from a distribution of possible values of the input quantities. This probability distribution can be based on the frequency, that is, a series of observations, or may be an a priori distribution. Uncertainties called Type A are calculated from a series of independent repeated observations and is the familiar statistically evaluated experimental standard deviation of the mean, while the uncertainties called Type B, are obtained by means of a series of observations other than statistical analysis, in other words, is obtained from an assumed probability density function based on the degree of belief that an event will occur.

\subsubsection{Type A standard uncertainty}

The uncertainty of Type $A$ is evaluated on the basis of the randomness of the sample values. Where possible sources of randomness originate from human actions, the environment and process itself on the measurement system. Hence, a good evaluation for this type of uncertainty is provided by the experimental standard deviation of the mean, which can be represented by Eq. (2).

$u_{A}=\sqrt{\frac{n-1}{n-3}} \cdot S_{\bar{q}}=\sqrt{\frac{n-1}{n-3}} \cdot \frac{\sqrt{\sum_{k=1}^{n}\left(q_{k}-\bar{q}\right)^{2} / n-1}}{\sqrt{n}}$

where $S_{\bar{q}}$ characterizes the dispersion of the results, $q_{k}$ represents the result of the $k$ th measurement and $\bar{q}$ represents the arithmetic mean of $n$ results considered. The term before $S_{\bar{q}}$ is the correction of Bayes, according to Kacker et al. [37]

\subsubsection{Type B standard uncertainty}

Beyond the intrinsic variability of the measurand, there is the variability that is added by the measurement system. It is desirable that the measurement systems have the smallest possible, i.e. negligible, effect on the measurand, although it is necessary to evaluate this component of uncertainty before stating that it is negligible. This component of uncertainty is called GUM uncertainty Type B. The Type $B$ evaluation of uncertainty uses means other than the static analysis of a series of repeated measurements at the time of the test. According to GUM, the proper use of all available information for a Type B evaluation of standard uncertainty can be obtained through the following: experience and knowledge, which can be achieved from practice, performance measurement based on the historical data method, uncertainties inherited from the calibration equipment and standards, and the range of environmental conditions, among others.

The most direct, though not necessarily the cheapest, way to evaluate uncertainty Type $B$, is available when there is a calibra- tion certificate of the measuring system. Ideally, this certificate should be issued by conducting experiments with instruments on the premises, which means that if you use a flow meter attached to an industrial chain, the calibration of the instrument should be performed in an operation on the factory floor during the manufacturing process.

\subsubsection{Combined standard uncertainty}

The effects of the combined action of several sources of uncertainty should be quantified by the combined uncertainty $[38,37]$. GUM is employed to propagate the estimates, standard uncertainties and correlation coefficients of input quantities from a linear approximation of the model that links the quantities input with the output, using the Taylor series around their averages. The combined standard uncertainty considering all of the independent input quantities is given by:

$u_{c}^{2}(y)=\sum_{i=1}^{N}\left[\frac{\partial f}{\partial x_{i}}\right]^{2} u^{2}\left(x_{i}\right)$

where, $\partial f / \partial x_{i}$ is the sensitivity coefficients, and describes how the output estimate $y$ varies with changes in the values of the input estimates $x_{1}, x_{2}, \ldots, x_{N}$. Each is a standard uncertainty evaluated as described in Section 6.1.1 (Type A evaluation) or as in Section 6.1.2 (Type B evaluation). When Eq. (3) is used to evaluate the uncertainty of a quantity measured directly, it takes the following form:

$u^{2}\left(x_{i}\right)=\sqrt{u_{A}^{2}+\sum_{j=1}^{n} c_{j}^{2} u_{b_{j}}^{2}}$

The estimated input $x_{1}, x_{2}, \ldots, x_{N}$ which makes a greater contribution to the value of the measurand will have the highest level of contribution, and therefore makes a greater contribution to the final uncertainty of $y$. For a comparison of the contribution of the uncertainties of the input variables, it is necessary to express the coefficient of contribution $h\left(y, x_{i}\right)$ on a relative scale (\%) for combined standard uncertainty. Kessel et al. [39] set out the following expression as a factor contributing to the uncorrelated input variables:

$h\left(y, x_{i}\right)=\left[\frac{u_{i}(y)}{u(y)}\right]^{2}=\left[\frac{\frac{\partial f}{\partial x_{i}} \cdot u\left(x_{i}\right)}{u(y)}\right]^{2}$

\subsection{Expanded uncertainty}

The expanded uncertainty is the range around the measurement result which covers a large proportion of the probability distribution, characterized by that result and its combined uncertainty. The expanded uncertainty $U$ is obtained by multiplying the combined standard uncertainty $u_{c}(y)$ by a coverage factor $k$.

$U=k \cdot u_{c}(y)$

The result of a measurement is then expressed as $Y=y \pm U$, where $Y$ is the value assigned to the measurand, and $y+U$ a $y-U$ is the interval that is expected to cover a large fraction of the distribution of values that can be attributed to $Y$. The coverage factor must be calculated from the values of the number of degrees of freedom and the standard uncertainty of each source of uncertainty in Eq. (7) Welch-Satterthwaite(W-S).

$$
v_{\text {eff }}=\frac{u_{c}^{4}(y)}{\sum_{i=1}^{N} \frac{\left[c_{i} u\left(x_{i}\right)\right]^{4}}{v_{i}}}
$$




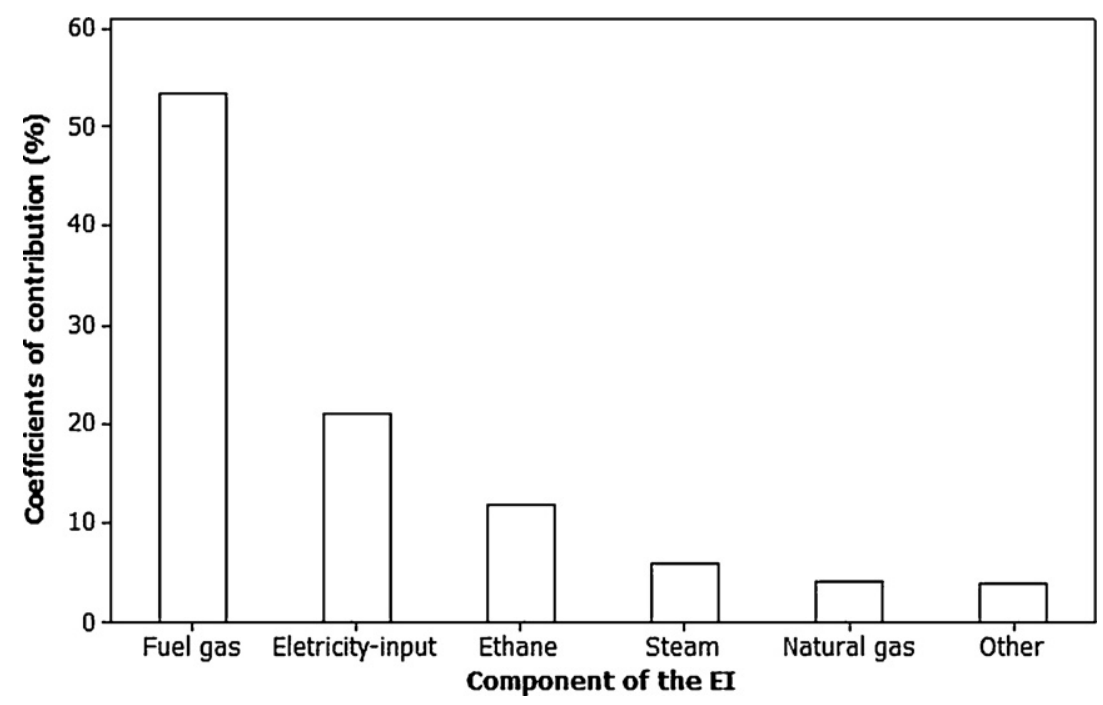

Fig. 1. Coefficient of the contribution of the major component of $E I$.

where $v_{\text {eff }}$ is the effective degree of freedom, $u_{c}(y)$ is the combined uncertainty, $u\left(x_{i}\right)$ is standard uncertainty associated with the $i$ th source of uncertainty, $v_{i}$ is the number of degrees of freedom associated with the $i$ th source of uncertainty and $N$ the total number of sources of uncertainties analyzed.

The $\mathrm{W}-\mathrm{S}$ formula provides an approximate solution to the problem of determining the confidence interval for the measurand. Using the formula in determining the $\mathrm{W}-\mathrm{S}, v_{\text {eff }}$ the coverage factor $k$ can be evaluated by a Student's $t$-distribution. The coverage factor not only depends on $k\left(v_{\mathrm{eff}}, p\right)$, but also the confidence level (probability of coverage) $p$ desired in the analysis of the expanded uncertainty. Thus, the coverage factor is called $k\left(v_{\text {eff }}, p\right)$ and the expanded uncertainty is expressed by $U=k_{p} u_{c}$. The value of $k$ is similar to the tabulated values of Student's $t$-distribution with effective degrees of freedom for a given level of confidence. The $\mathrm{W}-\mathrm{S}$ formula depends on several hypotheses to be strictly valid: all the quantities must have normal PDF, all the input quantities must be independent and the linear approximation model of the measurand must also be appropriate ([22], clause 5.1.2 and 5.1.5). However, in most cases these assumptions are not fully met see Martins et al. [40] who outline a number of appropriate treatment alternatives for these situations. When the indicator is represented by a non-linear model or when the assumptions referred to above are not appropriate, the application of the technique of Monte Carlo simulation, described in the GUM Supplement 1 and developed by BIPM et al. [41] and Martin et al. [40] is recommended.

\section{Case study}

The monitoring process in petrochemical industries is undertaken through the use of indicators calculated over periods of time and drawing on data from the process. The indicators show the times when the operation took place in a stable way and in times of highly variable production.

In this study a method is used to evaluate the uncertainty of the energy indicator at a petrochemical unit. This energy indicator represents the amount of energy consumed in the production process. The goal of the company is to reduce the rate by $3 \%$, with investment being made in projects and personnel. A reduction in this indicator can mean lower fuel consumption, less $\mathrm{CO}_{2}$ pollution and a fall in production costs. Validation is an important stage in the evaluation of this indicator and it is necessary to calculate the uncertainty to ensure that $3 \%$ represents a significant reduction in fuel and production costs. We provide an estimate of evaluate the uncertainty of the energy indicator and its sensitivity to changes in the operation process. The structure of the indicator was displayed in a spreadsheet to help evaluate the uncertainty of the indicator as well as its sensitivity to each of the components of the model.

\subsection{Energy indicator}

The energy indicator (EI) has been used to monitor the energy consumption relative to the rate of production in the period. The study of uncertainty arose from the need to optimize the production of inputs, with regard to reducing energy consumption for a possible operating point and has achieved real results. According to ISO $14031, E I$ can be categorized as an indicator of operating performance and classified as an aggregate, composed of the sum of 17 components in the numerator $(C N)$ with 27 components in the denominator $(C D)$ of various sources (Eq. (8)).

$$
E I=\frac{\sum_{i=1}^{17} C N}{\sum_{j=1}^{27} C D}
$$

The main feature of the components of the numerator is that it should be used in the generation or transmission of energy entering the volume control of the company, since the denominator refers to the products that are stocked or sold. Each component is the sum of the value from thee measuring device that monitors the stream in real time, Fig. 2.

\subsection{Applying the GUM methodology}

The procedure used to evaluate the uncertainty followed the recommendations of GUM, as described in Section 6. The evaluate of uncertainty was based on the method for propagation of uncertainties of input quantities ( $C N$ and $C D$ ) for the magnitude of output $(E I)$. In each quantity, the input was regarded as comprising the contributions of Type A (Eq. (2)) and Type B uncertainties, where the former concerns process variability and the latter the quality of measurement.

After identifying the model (Eq. (8)), we adopted a procedure to evaluate the sources of uncertainty, as well as the Type A and Type $\mathrm{B}$ uncertainties. The uncertainty is dependent on the behav- 
Table 2

Source of measurement uncertainty and uncertainty values Type B.

\begin{tabular}{ll}
\hline Source of uncertainty & Uncertainty (\%) \\
\hline Orifice plate & 3.50 \\
Measure mass & 0.80 \\
Orifice plate 4 holes & 2.00 \\
Tank & 0.20 \\
Gases & 1.00 \\
Liquid & 0.70 \\
Steam & 2.00 \\
Eletricity input & 1.00 \\
Eletricity output & 1.00 \\
\hline
\end{tabular}

Table 3

Estimation of uncertainty of Type A gas fuel.

\begin{tabular}{ll}
\hline Daily production of gas fuel (kg/day) & $50.9 \mathrm{E}+05$ \\
The mean of the uncertainties Type A (kg/day) & $50.9 \mathrm{E}+04$ \\
Combined uncertainty of fuel gas produced (kg/day) & $1.0 \mathrm{E}+05$ \\
Coefficient of variation of the combined uncertainty of the & 2.0 \\
$\quad$ fuel gas or relative uncertainty (\%) & \\
\hline
\end{tabular}

ior of industrial production and will thus fluctuate over a period of time. Therefore of this, we chose a fixed day which the engineering dept regarded as suitable for providing stable conditions. An electronic spreadsheet was prepared to allow some future changes in the variable values used in this research.

The Type A uncertainties of $C N$ and $C D$ should be obtained by analyzing the data by means of a measurement device used in the operating process. Nevertheless, there are more than 1000 measurement devices which means that conducting an analysis of all the measurement devices in industry would be an arduous task. In view of this , we conducted an accurate analysis of the most important component and we treated the uncertainty of Type A of the measurement devices of the other components as the mean of the uncertainty of the important component. The most important component is fuel gas which makes up $70 \%$ of all the energy consumed in the industry. The contribution of the indicator for each components is represented by the coefficient of the contribution [40] (Fig. 1).

It is important to bear in mind that the structure of the indicator is the most important part at this stage because it allows changes to be made in the values when doubt exists. The Type A uncertainties were evaluated with the aid of Eq. (2) and the data were measured each second.

The analysis of Type B uncertainties is used to find out about the measuring device used in the measurement. We analyzed the measuring devices and a table was prepared to show the typical uncertainties that are caused by the petrochemical industry in question. This Table is already being used in the data reconciliation and on-line process optimization of the industry. Table 2 displays the sources and their related uncertainties. The uncertainty values of the orifice plate meter and mass were evaluated on the basis of the average values found in the internal research (reports of the operation). The uncertainty values of inputs coming from the tanks, gas, liquid, steam sales, electrical supplies were drawn from the monthly reports.

All these factors were evaluated through the combined standard uncertainty (Eq. (3)) of $C N$ and $C D$, and took account of all the input variables of the independent model (Eq. (8)). The degree of freedom is calculated using the Welch-Satterthwaite equation(Eq. (7)), which treats the probability density functions of the components of the numerator and denominator as normal and independent.

The analysis of the Type A uncertainties of the fuel gas is achieved by identifying all the fuel gas meters and the information flow values collected by the company. Table 3 shows the estimate of Type A uncertainty for the fuel gas.
The evaluated of the uncertainty of the indicator of energy consumption per ton of petrochemicals produced is based on the contribution of process variability (uncertainty Type A) and quality measurement (uncertainties Type B). From the data obtained, we also raised the degree of freedom, considering 30 measurements for each meter, thus implying a degree of freedom of 29. By applying the Welch-Satterthwaite formula (Eq. (8)), we calculated the degree of freedom of each component and then the overall indicator, and obtained a value of 333 for the degree of freedom. With the degree of freedom at a confidence level of $90 \%$ a coverage factor of 2 was obtained. In this context, due to poor knowledge about the uncertainties, several scenarios arose ranging from the uncertainties Types A and B for the input quantity, and seven possibilities were obtained which are displayed in Table 4.

From Table 4 it can be observed that, if scenario 1 is adopted, the energy indicator can be shown as:

$E I=(20.0 \pm 0.2) \frac{\mathrm{GJ}}{\mathrm{t}}$

where the number following the symbol \pm is the numerical value of $U=k \cdot u_{c}$, an expanded uncertainty, with $U$ given by $u_{c}=0.1 \mathrm{GJ} / \mathrm{t}$, a combined standard uncertainty and a coverage factor $k=1.67$ based on the $t$-distribution for $v_{\text {eff }}=69$ degrees of freedom. $U$ defines an interval evaluated to have a $90 \%$ confidence interval.

Alternatively, if scenario 7 is adopted, the energy indicator can be shown as:

$E I=(20.0 \pm 0.8) \frac{\mathrm{GJ}}{\mathrm{t}}$

where $u_{c}$ changes to $0.5 \mathrm{GJ} / t$ and $k$ to 1.65 based on the $t$-distribution for $v_{\text {eff }}=361$ degrees of freedom for the same $90 \%$ confidence interval.

Fig. 2 shows the main components that contribute to a quantitative calculation of the $I E$ and thus influence the final uncertainty of the indicator. A sensitivity test of the indicator based on Eq. (5) shows that the component of the calculation that most influences the final value of uncertainty is the fuel gas. This means that it is these meters that most need to be improved so that the uncertainty indicator can be significantly reduced.

The process of estimating the uncertainty was influenced by the method of calculating the daily flow. Before the system was implemented for the reconciliation of the corporate data, this calculation was based on information that had been memorized throughout the day. After the implementation of the reconciler, this information was collected every minute, and after this its value was calculated on the basis of the number of minutes of the day. These two procedures were tested in the evaluated daily flow rate of a variable and little difference was observed between the two forms of calculation.

The chart above (Fig. 2) shows the values measured minute by minute and the mean throughout the day (black horizontal line). Using the first calculation (information that had been memorized throughout the day), the value at the end of the day of production is calculated by integrating the area within the curve of the flow of fuel gas; this would be the measurement of the total amount in the second format of the calculation (after the implementation of the reconciler) which is obtained through the mean daily flow rate and then multiplied by the time interval required for collecting information. The sum of the area is shown below the black line. The results of both procedures are described in Table 5 .

This result shows that the two ways of calculating the daily flow are very close. The same procedure was adopted in this paper as was used in the reconciliation of data - the daily flow from the multiplication of the average flow time interval of interest.

In discussions with the engineering team (operational, monitoring and instrumental) a consensus was reached that the most realistic and safest scenario is the 7 , which means that the uncertainty that the company adopted for the energy indicator was 
Table 4

Scenarios for estimating uncertainty of $E I$.

\begin{tabular}{|c|c|c|c|c|c|c|c|}
\hline \multirow[t]{2}{*}{ Source of uncertainty } & \multicolumn{7}{|c|}{ Scenarios } \\
\hline & 1 & 2 & 3 & 4 & 5 & 6 & 7 \\
\hline Orifice plate (Type B) & $3.5 \%$ & $3.5 \%$ & $3.5 \%$ & $7.0 \%$ & $7.0 \%$ & $7.0 \%$ & $7.0 \%$ \\
\hline Mass (Type B) & $0.8 \%$ & $0.8 \%$ & $0.8 \%$ & $1.6 \%$ & $1.6 \%$ & $1.6 \%$ & $1.6 \%$ \\
\hline Orifice plate 4 holes (Type B) & $2.0 \%$ & $2.0 \%$ & $2.0 \%$ & $4.0 \%$ & $4.0 \%$ & $4.0 \%$ & $4.0 \%$ \\
\hline Tank (Type B) & $0.2 \%$ & $0.2 \%$ & $0.2 \%$ & $0.4 \%$ & $0.4 \%$ & $0.4 \%$ & $0.4 \%$ \\
\hline Gas (Type B) & $1.0 \%$ & $1.0 \%$ & $1.0 \%$ & $2.0 \%$ & $2.0 \%$ & $2.0 \%$ & $2.0 \%$ \\
\hline Liquid (Type B) & $0.7 \%$ & $0.7 \%$ & $0.7 \%$ & $1.4 \%$ & $1.4 \%$ & $1.4 \%$ & $1.4 \%$ \\
\hline Steam (Type B) & $2.0 \%$ & $2.0 \%$ & $2.0 \%$ & $4.0 \%$ & $4.0 \%$ & $4.0 \%$ & $4.0 \%$ \\
\hline Electricity (input) (Type B) & $1.0 \%$ & $1.0 \%$ & $1.0 \%$ & $2.0 \%$ & $2.0 \%$ & $2.0 \%$ & $2.0 \%$ \\
\hline Electricity (output) (Type B) & $1.0 \%$ & $1.0 \%$ & $1.0 \%$ & $2.0 \%$ & $2.0 \%$ & $2.0 \%$ & $2.0 \%$ \\
\hline Uncertainty of fuel gas (Type B) & $3.5 \%$ & $3.5 \%$ & $7.0 \%$ & $7.0 \%$ & $7.0 \%$ & $7.0 \%$ & $7.0 \%$ \\
\hline Type A uncertainty of all variables & $1.0 \%$ & $2.0 \%$ & $1.0 \%$ & $1.0 \%$ & $2.0 \%$ & $4.0 \%$ & $10.0 \%$ \\
\hline Expanded uncertainty of the energy indicator (\%) & $1 \%$ & $1 \%$ & $1 \%$ & $1 \%$ & $2 \%$ & $2 \%$ & $4 \%$ \\
\hline Expanded uncertainty of the energy indicator $(\mathrm{GJ} / \mathrm{t})$ & 0.2 & 0.2 & 0.2 & 0.3 & 0.3 & 0.4 & 0.8 \\
\hline Value of the energy indicator $(\mathrm{GJ} / \mathrm{t})$ & & & & 20.0 & & & \\
\hline
\end{tabular}

Note 1: Scenario 1 - Type B uncertainty as used in the reconciliation of balance sheet data of hydrocarbons.

Note 2: Scenario 2 - Type A uncertainty double uncertainty Type A of the scenario 1.

Note 3: Scenario 3 - Type B uncertainty of the fuel gas twice the uncertainty Type B gas fuel of the scenario 1.

Note 4: Scenario 4 - Type B uncertainties of all the instruments twice the uncertainty Type B of the scenario 1.

Note 5: Scenario 5 - Type B uncertainties of all instruments and uncertainty of Type A double uncertainty Type B and Type A, respectively, of the scenario 1.

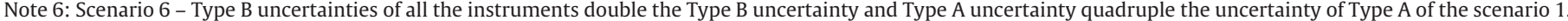

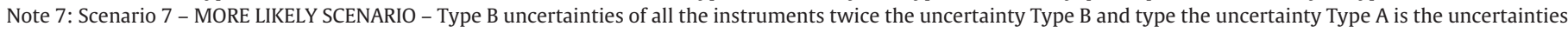
fuel gas type.

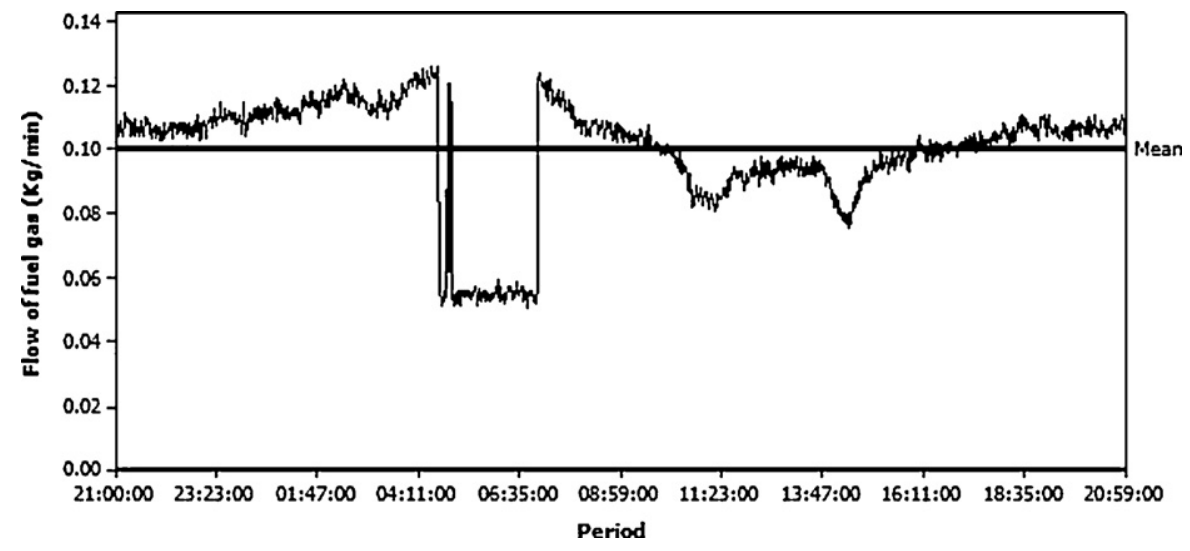

Fig. 2. Chart with the measures minute to the minute of the gas fuel.

Table 5

Calculation of averages by two procedures.

\begin{tabular}{lc}
\hline Mean flow (kg/min) & 0.09972 \\
Time interval (min) & 1441 \\
$\begin{array}{l}\text { Daily flow using the mean rate multiplied by the time interval } \\
\text { (kg/day) }\end{array}$ & 143.7018 \\
$\begin{array}{l}\text { Daily flow by the direct sum of the flows minute by minute } \\
\quad(\mathrm{kg} / \text { day })\end{array}$ & 143.4032
\end{tabular}

$(20.0 \pm 0.8) \mathrm{GJ} / \mathrm{t}$, or in other words, $4 \%$ of the measured value. This result has changed the way the company sets its goals for improving efficiency, because it was found that whether or not these goals could be met, merely depends on the variability of the process because they were within the range of uncertainty of the indicator.

\section{Conclusions}

The evaluation of data quality for obtaining the kind of environmental indicators that are most appropriate for a given process is one of the most important stages in the correct interpretation of an indicator of environmental or operational efficiency.

The methodology based on GUM offered here for the evaluation and assessment of uncertainty when applied to a power indica- tor at a petrochemical company, has led us to reach the following conclusions:

- It can be assumed that the most likely $7^{\circ}$ scenario is $4 \%$ of the value of the indicator or $0.8 \mathrm{GJ} / \mathrm{t}$, based on calculations made in January 2008 and that it had an EI of $20.0 \mathrm{GJ} / \mathrm{t}$.

- The most important component in estimating the uncertainty of the indicator is the flow of the fuel gas.

- It is important to raise measurements involving the variability of the process because, in addition to improving the value of the indicator, it can help to lower the uncertainty of this indicator.

In general, when evaluating the performance of an organization through indicators, a tool used for decision-making must take into account their uncertainty, even in an industrial environment where there is variability in the process. Hence, it is essential to obtain the knowledge of how the indicator is constructed and to be aware of its limitations in measuring the quality of each of its components. In other words, it is essential to evaluated the uncertainty of each component of the indicator and the propagation of the uncertainty of the indicator itself. 
The case study was undertaken in an industrial environment which is reasonably under control and subject to less variability than in other media. This shows that the uncertainty of the indicator is significant and should not be assumed to be negligible. In other environments, where the operational conditions or environment cannot be controlled or known, the indicators, be they relative or absolute, should have an even greater uncertainty. In view of this, it is recommended that the uncertainty of the indicators be evaluated in any situation or the wrong decisions may be taken.

\section{Acknowledgement}

We would like to thank the Coordination for the Improvement of Higher Education Personnel - CAPES, for its financial support for this research.

\section{References}

[1] I.O. for Standardization, Environmental Management - Environmental Performance Evaluation - Guideline, ISO 14031; 1999.

[2] Mendes C, Esquerre KOPS, Kiperstok A, de Araújo Kalid R. Construçào e análise systemática de indicadores de efluentes industriais. In: 25 Congresso Brasileiro de Engenharia Sanitária e Ambiental; 2009.

[3] Kiperstok A, Mendes C, Kalid RA, Sales E, Pachego Filfo JGA. Uma política nacional de meio ambiente focada na produçào mais limpa: elementos para discussào. Bahia, Análise \& Dados 2001;10:326-32.

[4] Cardoso LMF. Indicadores de produçào limpa: uma proposta para análise de relatórios ambientais de empresas. Master's thesis, Departamento de engenharia sanitária e ambiental - Universidade Federal da Bahia; 2004.

[5] Morhardt JE, SarahBaird KF. Scoring corporate environmental and sustainability reports using gri iso 14031 and other criteria. Eco-Management and Auditing 2000 2002;9:215-33.

[6] Berkhout F, Hertin J, Moll S, Schepelmenn P. Indicators for monitoring integration of environment and sustainable development in enterprise policy. Tech. rep., University of Sussex; 2001.

[7] Diakaki C, Grigoroudis E, Stabouli M. A risk assessment approach in selecting environmental performance indicators. Management of Environmental Quality: An International Journal 2006;17:126-39.

[8] Henri J-F ois, Journeault M. Environmental performance indicators: an empirical study of canadianmanufacturing firms. Journal of Environmental Management 2008;87:165-76.

[9] Hermann B, Kroeze C, Jawjit W. Assessing environmental performance by combining life cycle assessment, multi-criteria analysis and environmental performance indicators. Journal of Cleaner Production 2007;15:1787-96.

[10] Jasch C. Environmental performance evaluation and indicators. Journal of Cleaner Production 2000:8:77-88.

[11] Johnston A, Smith A. Environmental performance indicators: the water industry of england and wales. Water and Environment Journal 2007;15:40-5.

[12] Olsthoorn X, Tyteca D, Wehrmeyer W, Wagner M. Environmental indicators for business: a review of the literature and standardisation methods. Journal of Cleaner Production 2001;9:453-63.

[13] Saengsupavanich C, Coowanitwong N, Gallardo WG, Lertsuchatavanich C. Environmental performance evaluation of an industrial port and estate: ISO14001, port state control-derived indicators. Journal of Cleaner Production 2009;17:154-61.

[14] Thoresen J. Environmental performance evaluation - a tool for industrial improvement. Journal of Cleaner Production 1999;7:365-70.

[15] Annette Evans VS, Evans TJ. Assessment of sustainability indicators for renewable energy technologies. Renewable and Sustainable Energy Reviews 2009;13:1082-8

[16] Emilio Lebre La Rovere LBO, Soares Jeferson Borghetti, Lauria T. Sustainable expansion of electricity sector: sustainability indicators as an instrument to support decision making. Renewable and Sustainable Energy Reviews 2010;14:422-9.
[17] Colombo M, Cesca M, Ingaramo A, Heluane H. Water and wastewater ecoefficiency indicators for the sugar cane industry. Journal of Cleaner Production 2009;17:487-95.

[18] Nordheim E, Barrasso G. Sustainable development indicators of the european aluminium industry. Journal of Cleaner Production 2007;15:275-9.

[19] Perotto E, Canzian R, Marchesi R, Butelli P. Environmental performance, indicators and measurement uncertainty in ems context: a case study. Journal of Cleaner Production 2008;16: 517-30.

[20] Dalia Streimikiene RC, Grundey D. Energy indicators for sustainable development in baltic states. Renewable and Sustainable Energy Reviews 2007;11:877-93.

[21] Bertrand-Krajewski J, Barraud JBS. Uncertainties, performance indicators and decision aid applied to stormwater facilities. Urban Water 2002;4:163-79.

[22] BIPM, IEC, IFCC, ILAC, ISO, IUPAC, IUPAP, OIML. Evaluation of measurement data - guide to the expression of uncertainty in measurement. joint committee for guides in metrology. Tech. rep., Bureau International des Poids et Measures, JCGM 100:2008, primeira versão desse documento referente ao ano de 1995 foi traduzido pelo INMETRO e ABNT, terceira edição brasileira em 2003; 2008.

[23] Cantarino AAA. Environmental performance indicators as a management tool and control the processes of environmental licensing of exploration and production of oil in offshore areas. Ph.D. thesis, Federal University of Rio de Janeiro: 2004.

[24] Veleva V, Ellenbecker M. Indicators of sustainable production: framework and methodology. Journal of Cleaner Production 2001;9:519-49.

[25] Global reporting initiative - gri, GLOBAL REPORTING INITIATIVE - GRI, Sustainability Reporting Guidelines; December 2009. http://www.globalreporting.org.

[26] Environment Australia. A guide to reporting against environmental indicators; June 2003. http://www.environment.gov.au/settlements/industry/ finance/publications/indicators/pubs/indicators.pdf.

[27] Tyteca D. On the measurement of the environmental performance of firms - a literature review and a productive efficiency perspective. Journal of Environmental Management 1996;46:281-308.

[28] Azzone G, Manzini R. Measuring strategic environmental performance. Business Strategy and the Environment 1994;3:1-14.

[29] EPA, Draft report on the environment. Tech. Rep. EPA 260-r-02-006, EPA; 2007.

[30] Unep/fidic/icc united nations environment programme e unep. Environmental management system training resource kit; 2001. http://earthwatch. unep.net/about/docs/indicat.htm.

[31] Organisation for economic co-operation and development e oecd.key environmental indicators. Paris: OECD Environment Directorate; 2004. http://www.oecd.org/.

[32] Von Bahr B, Hanssen OJ, Vold M, Pott G, Stoltenberg-Hansson E, Steen B. Experiences of environmental performance evaluation in the cement industry: data quality of environmental performance indicators as a limiting factor for benchmarking and rating. Journal of Cleaner Production 2003;11;713-20.

[33] Tsoulfas GT, Pappis CP. A model for supply chains environmental performance analysis and decision making. Journal of Cleaner Production 2008;16:1647-57.

[34] de Andrade EL. Introduçàoà pesquisa operacional: mátodos e modelos para análise de decisào. 2nd ed. LTC; 2000.

[35] Howarth P, Redgrave F. Metrology - in short; 2008.

[36] BIPM, IEC, IFCC, ILAC, ISO, IUPAC, IUPAP, OIML. International vocabulary of metrology: basic and general concepts and associated terms (vim).joint committee for guides in metrology. Tech. rep., Bureau International des Poids et Measures, JCGM 200:2008, documento traduzido pelo INMETRO, primeira edição brasileira em 2009; 2008.

[37] Kacker R, Sommer K-D, Kessel R. Evolution of modern approaches to express uncertainty in measurement. Metrologia 2007;44(6):513-29.

[38] Albertazzi A. Fundamentos de metrologia científica e industrial. Manole; 2008

[39] Kessel R, Kacker R, Berglund M. Coefficient of contribution to the combined standard uncertainty. Metrologia 2006;43(4):189-S195.

[40] Martins MAF, Kalid R, Nery GA, Teixeira LA, Gonçalves GAA. Comparação entre os métodos linear e não linear para estimativa da incerteza de medição. Submetido ao periódico Controle \& Automação (em fase de revisão).

[41] BIPM, IEC, IFCC, ILAC, ISO, IUPAC, IUPAP, OIML. Evaluation of measurement data-supplement 1 to the guide to the expression of uncertainty in measurement-propagation of distributions using a monte carlo method. Tech. rep., Joint Committee for Guides in Metrology, Bureau International des Poids et Measures, JCGM 200:2008; 2008. 